\title{
Os índices pluviais e o turismo de Caruaru - PE, Brasil
}

\author{
Rain index and tourism in Caruaru - PE, Brazil \\ Índice de lluvia y turismo en Caruaru - PE, Brasil
}

Recebido: 04/11/2021 | Revisado: 15/11/2021 | Aceito: 18/11/2021 | Publicado: 28/11/2021

Raimundo Mainar de Medeiros

ORCID: https://orcid.org/0000-0001-7361-1281

Universidade Federal Rural de Pernambuco, Brasil

E-mail: mainarmedeiros@gmail.com

Moacyr Cunha Filho

ORCID: https://orcid.org/0000-0002-3466-8143

Universidade Federal Rural de Pernambuco, Brasil

E-mail: Moacyr.cunhafo@ufrpe.br

Manoel Viera de França

ORCID: https://orcid.org/0000-0003-4973-9327

Universidade Federal Rural de Pernambuco, Brasil

E-mail: manoelvieira.ufrpe@gmail.com

Romildo Morant de Holanda

ORCID: https://orcid.org/0000-0001-7945-3616

Universidade Federal Rural de Pernambuco, Brasil

E-mail: romildomorant@gmail.com

Luciano Marcelo Fallé Saboya

ORCID: https://orcid.org/0000-0002-7586-6867

Universidade Federal de Campina Grande, Brasil

E-mail: 1saboya@hotmail.com

Wagner Rodolfo de Araújo

ORCID: https://orcid.org/0000-0001-7203-0338

Universidade Estácio de Sá, Brasil

E-mail: wagneraraujops@gmail.com

\section{Resumo}

A convivência entre o turismo, tempo e clima já foi representado por vários estudos regional e mundial, tem-se como objetivo realizar uma análise dos índices pluviais entre o período de 1913 a 2016 visando o apoio ao turismo urbano e rural no município de Caruaru. Esta análise é relevante, uma vez que a área estudada se caracteriza por possuir uma variabilidade das chuvas e uma diversidade de impactos das precipitações de grande significado na área estudada. Os dados pluviométricos foram adquiridos da Agência Pernambucana de Água e Clima, onde se utilizou de cálculos simplificados estatisticamente para definir, média, desvio padrão, coeficiente de variância, máximos e mínimos valores absolutos ocorridos, utilizou-se da série para definir a quadra, o trimestre e o mês chuvoso e seco. O município tem potencial paisagístico e de comércio para as atividades turísticas. A chuva não se revelou elemento impeditivo a pratica do turismo. Registrou-se ano com condições favoráveis às práticas da recreação e do lazer. O mês de junho com chuvas moderadas a forte em fins de semana podem ter prejudicado totalmente as atividades turísticas de campo, nos demais meses os índices pluviais indicaram boas condições para o seu desenvolvimento turístico rural e urbano. No período seco, evidenciou-se redução na quantidade das precipitações e registraram-se chuvas isoladas e ocasionais de magnitude variada em curto intervalo de tempo.

Palavras-chave: Variações climáticas; Análise climáticas; Recursos naturais.

\begin{abstract}
The coexistence between tourism, weather and climate has already been represented by several regional and world studies, the objective is to carry out an analysis of the rainfall indices between the period from 1913 to 2016 aiming at supporting urban and rural tourism in the municipality of Caruaru. This analysis is relevant, since the studied area is characterized by a rainfall variability and a diversity of rainfall impacts of great significance in the studied area. The pluviometry data were acquired from the Pernambuco State Water and Climate Agency, where statistically simplified calculations were used to define mean, standard deviation, coefficient of variance, maximum and minimum absolute values. Quarter and the rainy and dry month. The municipality has potential landscaping and trade for tourism activities. The rain did not prove to be an impediment to the practice of tourism. Year was registered with conditions favorable to the practices of recreation and leisure. The month of June with moderate to strong rains on weekends may have totally
\end{abstract}


hampered the tourist activities of the field, in the other months the rainfall indices indicated good conditions for its rural and urban tourism development. In the dry period, there was a reduction for rainfall and isolated and occasional rains of varying magnitude were recorded in a short period.

Keywords: Climatic variations, Climate analysis, Natural resources.

\section{Resumen}

La convivencia entre turismo, meteorología y clima ya ha sido representada por varios estudios regionales y mundiales, el objetivo es realizar un análisis de las tasas de precipitación entre el período 1913 a 2016, con el objetivo de apoyar el turismo urbano y rural en el municipio de Caruaru. Este análisis es relevante, ya que el área de estudio se caracteriza por tener una variabilidad de precipitaciones y una diversidad de impactos de precipitación de gran importancia en el área de estudio. Los datos de precipitación fueron adquiridos de la Agencia de Agua y Clima de Pernambuco, donde se utilizaron cálculos estadísticamente simplificados para definir la media, desviación estándar, coeficiente de varianza, valores absolutos máximos y mínimos ocurridos, la serie se utilizó para definir el cuadrado, el trimestre y el mes lluvioso y seco. El municipio tiene potencial paisajístico y comercial para la actividad turística. La lluvia no fue un impedimento para la práctica del turismo. Se registró un año con condiciones favorables para las prácticas de recreación y esparcimiento. El mes de junio con lluvias moderadas a fuertes los fines de semana pudo haber comprometido totalmente las actividades turísticas en el campo, en los demás meses el índice de precipitaciones indicó buenas condiciones para su desarrollo turístico rural y urbano. En el período seco, hubo una reducción en la cantidad de precipitación y se registraron lluvias aisladas y ocasionales de diversa magnitud en un corto período de tiempo.

Palabras clave: Variaciones climáticas; Análisis de clima; Recursos naturales.

\section{Introdução}

O turismo é, indiscutivelmente, um fato socioeconômico, político, cultural dos mais expressivos das sociedades e representa uma das mais importantes formas de reprodução de capital/captação de divisas. O homem tenta demonstrar aspectos de seu ambiente procurando lugares e maneiras que satisfaçam suas necessidades de bem estar e lazer, atribuindo valores às coisas que produzem consequências consideradas por ele e pela sociedade como desejáveis. Assim, um elemento natural torna-se um recurso quando o homem encontra uma forma de empregá-lo para seu próprio benefício (Bartholo, Sansolo \& Bursztym 2011).

Bartholo, Sansolo e Bursztym (2011) afirmaram que o turismo atualmente é um dos ramos da economia que mais movimentam capitais e condiciona recursos financeiros e humanos ao seu desenvolvimento local ou regional. As pessoas, sempre que podem, realizam planejamento com almejo a viajar por período longo ou curto em suas férias e/ou em feriados prolongados para lugares diferentes de onde habitam.

O turismo de tal maneira exerce influências benéficas como maléficas sobre os ambientes, afetando assim os recursos de formas contraditórias, agregando irreversivelmente as maiores atrações que o justificarem e o atraírem, erodindo recursos naturais, quebrando a unidade e a escala da paisagem tradicional e suas construções características. Por outro lado, protegendo e estimulando o interesse dos turistas e autoridades regionais e locais para apreciação do valor ambiental. Molina apud Dias (2003).

Medeiros, Souza e Gomes Filho (2014) verificou-se que o Índice de Anomalia de Chuva pode ser utilizado como ferramenta para o acompanhamento climático de uma localidade, nesse caso a bacia hidrográfica do rio Uruçuí Preto, além de ser utilizado para regionalização, podendo também, através desse monitoramento gerar prognósticos e diagnósticos da climatologia local. A partir dos critérios de classificações tomados com bases nos desvios percentuais classificaram-se os meses e anos dos locais que compõem a bacia hidrográfica, onde se obteve oscilações de extremamente chuvoso a extremamente seco.

A partir da premissa de que o clima tem relevância ao desenvolvimento de atividades turísticas, seus elementos constituintes não podem ser ignorados nem desprezados, como: temperatura do ar, umidade relativa do ar, pluviometria, intensidade e direção predominante do vento, insolação, cobertura de nuvem entre outros. De acordo com a ocasião e com o tipo de atividade turística que se pretenda praticar, um elemento pode ter preponderância sobre os outros, como, por exemplo, 
temperatura e insolação elevada em ida à praia; intensidade do vento em atividade de paraquedismo, umidade relativa baixa para competições atléticas em ambientes abertos e o tipo de roupa a ser usada.

Nas latitudes tropicais tem-se como um dos principais elementos climático oscilante e causador de conflitos na vida das comunidades e pessoas, sobretudo àquelas que vivem em centros urbanos desenvolvidos, é a precipitação. A precipitação é fonte de noticias em todos os meios de comunicação, com extensa repercussão, por causar excesso e/ou falta de chuva, provocando alagamento, inundações, cheias, assoreamento e transbordamentos de lagoas, lagos, riachos, córregos e rios, escoriamento, sangramento ou secagem de grandes represas, afeta ou não a área de lazer e ao turismo local e regional, causa ainda transtorno aos tomadores de decisões locais e regionais e/ou mesmo governamental (Marengo, Alves, Beserra \& Lacerda 2011).

A convivência entre o turismo, tempo e clima já foi representado por vários estudos regional e mundial. Sendo o clima um elemento de fundamental importância ao desenvolvimento das atividades turísticas diversas autores realizaram e continuam realizando pesquisas e desenvolvendo artigos com informações diversas e seguras aos turistas. Existe aceitação entre os estudiosos do turismo e climatologista que as atividades turísticas de determinado local e/ou área estão intimamente ligadas às condições climáticas atuantes segundo afirmam os autores (Barbiére 1981; Besancenot 1990). Contudo é perceptível que locais cujos climas apresentem excessos (insolação, variabilidade de umidade e temperaturas extremas, chuva, vento) possuem menor potencial atrativo quando comparados a locais de condições climáticas flexíveis, embora, em algumas situações estas flutuações depender do desejo específico do turista, que tais circunstâncias sejam apreciadas.

Compreende-se que a incidência de chuva seria capaz de atrapalhar o dia de um turista que busca passar períodos de lazer e descontração em áreas que proporcionem experiências diferentes da sua rotina, nos espaços rurais e/ou naturais conforme o autor Beni (2001).

Oliveira, Medeiros e Silva Brito (2013) demostraram a contribuição dos elementos meteorológicos para o turismo religioso do município de Lagoa seca - PB, a recomendação é quanto às variações da amplitude térmica aos visitantes, principalmente os que sofrem de doenças respiratórias, pois irá passar por dificuldade de respiração nos trajetos.

Tele, Matos e Medeiros (2014) demonstraram as potencialidades turísticas no município de Barbalha e as influencias meteorológicas e a previsão de tempo confiável aos visitantes os quais devem utilizar-se de acessórios adequados aos passeios e proteções a pele durante o dia.

Medeiros, Borges e Patrício (2012) demonstrar as potencialidades turísticas do município de Cabaceiras e a contribuição das informações mais confiáveis de tempo e clima aos seus visitantes, baseado em dados meteorológicos como temperatura, umidade relativa do ar, velocidade do vento, direção predominante do vento, insolação total e nebulosidade. Concluíram que é de suma importância às informações dos elementos meteorológicos como variações de temperaturas, meses de menores e maiores ocorrência de chuvas, as variabilidades da umidade relativa do ar e suas consequências para os turistas, à flutuação da radiação solar, vento, evaporação, evapotranspiração cobertura de nuvens, para que o visitante utilize-se de acessório mais adequado aos seus passeios, como roupas adequadas para ambos os períodos e a utilizações de proteção a cabeça, portando água e protetor solar para que possam ter um passeio entre a normalidade de conforto.

A precipitação pluviométrica é uma variável climática que possui uma distribuição aleatória no espaço e no tempo, exercendo forte influência nas condições ambientais. Os equipamentos comumente utilizados para medir a quantidade de chuva que cai sobre uma região são chamados de pluviômetros e pluviógrafos. Existindo um conjunto destes, forma-se uma rede que possibilita o estudo climatológico de uma determinada área seja uma bacia hidrográfica ou o limite administrativo de um município em conformidade com os autores (Tucci 2001; Moulin 2005; Caram 2007). 
Objetiva-se uma análise dos índices pluviais entre o período de 1913 a 2016 visando o apoio ao turismo urbano e rural. Esta análise é relevante, uma vez que a área estudada se caracteriza por possuir uma variabilidade das chuvas e uma diversidade de impactos das precipitações de grande significado na área estudada.

\section{Material e Métodos}

O município de Caruaru está localizado na mesorregião Agreste e na Microrregião do Vale do Ipojuca do Estado de Pernambuco, limitando-se ao norte com Toritama, Vertentes, Frei Miguel e Taguatinga do Norte, ao sul com Altinho e Agrestina, a leste com Bezerros e Riacho das Almas, e a oeste com Brejo da Madre de Deus e São Caitano. A área municipal ocupa 928,1 $\mathrm{km}^{2}$ e representa $0,94 \%$ do Estado de Pernambuco, sendo que $16,6 \mathrm{~km}^{2}$ estão em perímetro urbano e os $903,9 \mathrm{~km}^{2}$ restantes formam a zona rural. A sede do município tem altitude de 554 metros e coordenadas geográficas de $08^{\circ} 17^{\prime} \mathrm{S}$ latitude e $35^{\circ} 58^{\prime} \mathrm{W}$ de longitude, distando 140,7 km da capital. Na Figura 1 tem-se a localização do município de Caruaru.

Figura 1. Localização do município de Caruaru - PE.

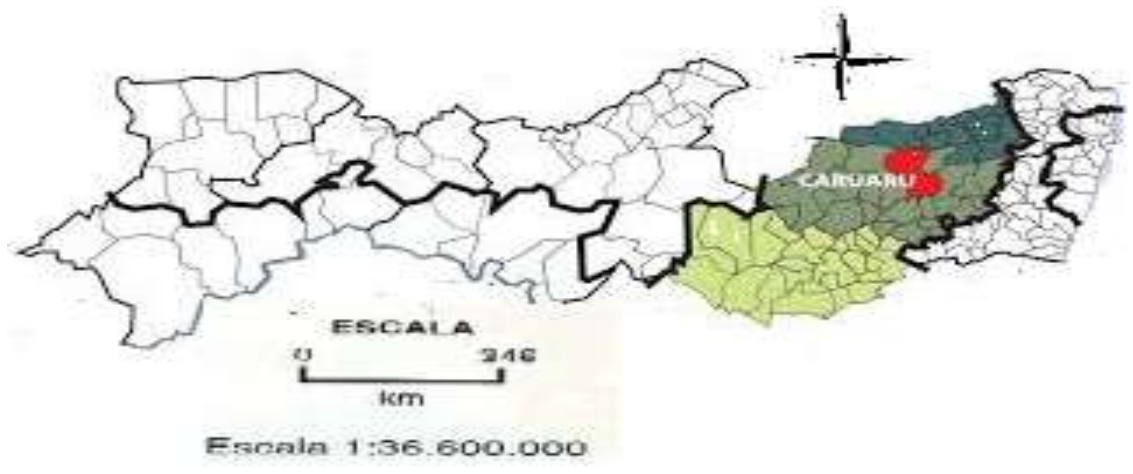

Fonte: Medeiros (2021).

O clima de Caruaru é do tipo semiárido BSh, possuindo verões quentes e secos e invernos amenos e chuvosos, tal classificação está de acordo com (Alvares, Stape, Sentelha, Gonçalves \& Sparover 2014; Medeiros, Holanda, Viana \& Silva 2018).

A quadra chuvosa se inicia em fevereiro com chuvas de pré-estação (chuvas que ocorrem antes da quadra chuvosa) com seu término ocorrendo no final do mês de agosto e podendo se prolongar até a primeira quinzena de setembro. $\mathrm{O}$ trimestre chuvoso centra-se nos meses de maio, junho e julho e os seus meses mais seco ocorrem entre outubro e dezembro. Os fatores provocadores de chuvas no município são a contribuição da Zona de Convergência Intertropical (ZCIT), formação dos vórtices ciclônicos de altos níveis (VCAS) quando seu centro posiciona-se sobre o oceano, influencia a contribuição dos ventos alísios de nordeste no transporte de vapor e umidade a quais condensam e forma nuvens provocando chuvas de moderadas a fortes, as formações das linhas de instabilidades, a orografia e suas contribuições locais formando nuvens e provocando chuvas de moderada a forte (Medeiros 2016).

Os dados pluviométricos foram adquiridos da Agência Pernambucana de Água e Clima (APAC, 2017) compreendido entre os anos de 1913 a 2016, se utilizou de cálculos simplificados estatisticamente para definir, média, desvio padrão, coeficiente de variância, máximos e mínimos valores absolutos ocorridos, utilizou-se da série para definir a quadra chuvosa e seca, o trimestre seco e chuvoso além do mês seco e chuvoso. 
A limitação dos recursos hídricos na atualidade é um importante condicionante ao desenvolvimento econômico e social, uma vez que, pode acarretar inúmeros desafios ao planejamento e gerenciamento deste recurso (Sousa et al., 2015). As falhas dentre a década de 90 pode ser explicada pela troca de responsabilidade na coleta dos registros pluviométricos da antiga (SUDENE 1990) para a atual (APAC 2017), neste período de transição as estações passaram por manutenção e outras foram implantadas em algumas cidades entre 1989 e 1992. Para tanto foram realizados preenchimentos de falhas, homogeneização e consistência nos referidos dados para poder-se trabalhar e fornecer informações confiáveis ao publico em geral.

\section{Resultados e Discussões}

Nas Figuras 2 e 3 têm-se algumas vistas aéreas e frontais do mercado da feira de Sulanca em Caruaru e das suas barracas nos arredores do mercado e Vista das barras da feira livre no mercado central de Caruaru. Agradecemos as fontes das imagens por permitir publicarmos as referidas fotos.

Figura 2. Vista aérea e frontal do mercado da feira de Sulanca em Caruaru e das suas barracas nos arredores do mercado.

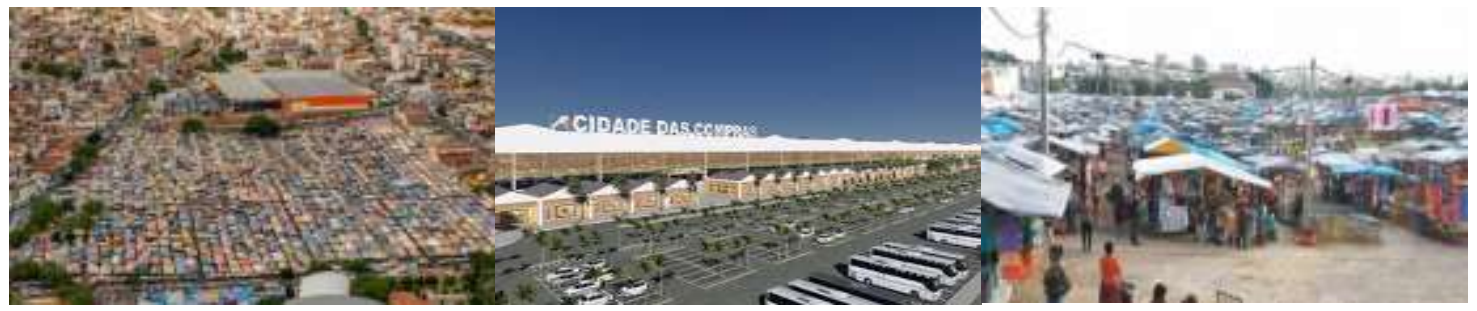

Fonte: Toritama-Jeans.com e TV Replay.

Figura 3. Vista das barras da feira livre no mercado central de Caruaru.

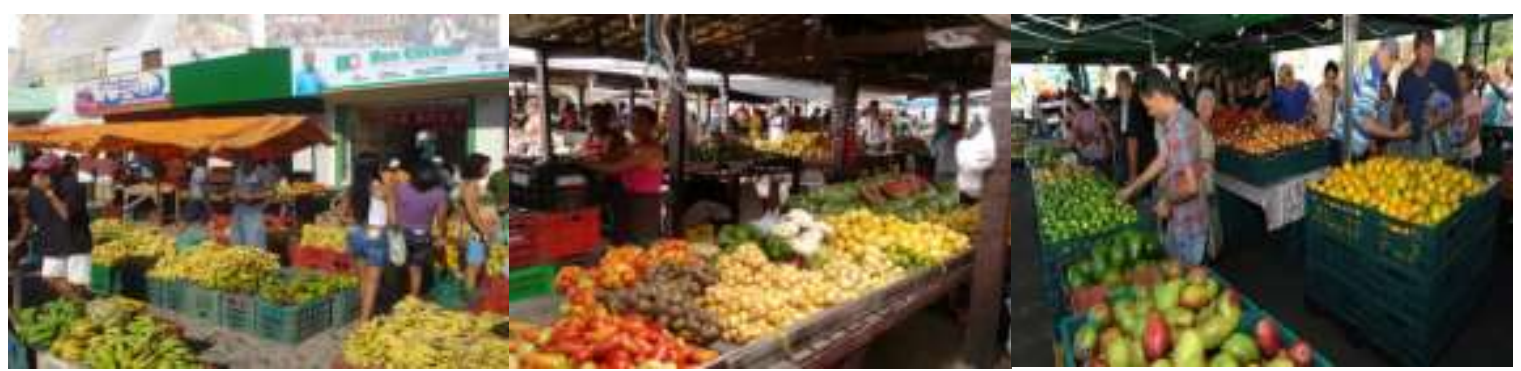

Fonte: Caruaru.pe.gov.br; liberdade.com.br e g1.blobo.com.

Na Figura 4 tem-se a distribuição média mensal e seu percentual dos índices pluviométricos do município de Caruaru PE ocorrido entre o período de 1913 a 2016. Nos meses de fevereiro a julho ocorrem 76\% do total precipitado do ano. Os meses de maio, junho e julho tem seus percentuais mensais de $14 \%, 16 \%$ e $14 \%$ representado o seu trimestre chuvoso. O trimestre seco que corresponde aos meses de outubro, novembro e dezembro tem contribuição de $2 \% ; 2 \%$ e $3 \%$ do valor anual do índice pluviométrico, por isso considerou-se como o trimestre mais seco. O mês considerado de baixos índices pluviométricos é o mês de outubro e tem $2 \%$ de seu valor anual esperado. O mês de junho considerado o mês de altas incidências pluviométricas com 16\% de ocorrências da cota anual. O mês de janeiro representa $6 \%$ do valor esperado anual, os meses de agosto e setembro têm $4 \%$ e $7 \%$ do valor pluviométrico anual e são considerados meses atípicos. 
Figura 4. Distribuição média mensal e seu percentual dos índices pluviométricos do município de Caruaru - PE ocorrido entre o período de 1913 a 2016.

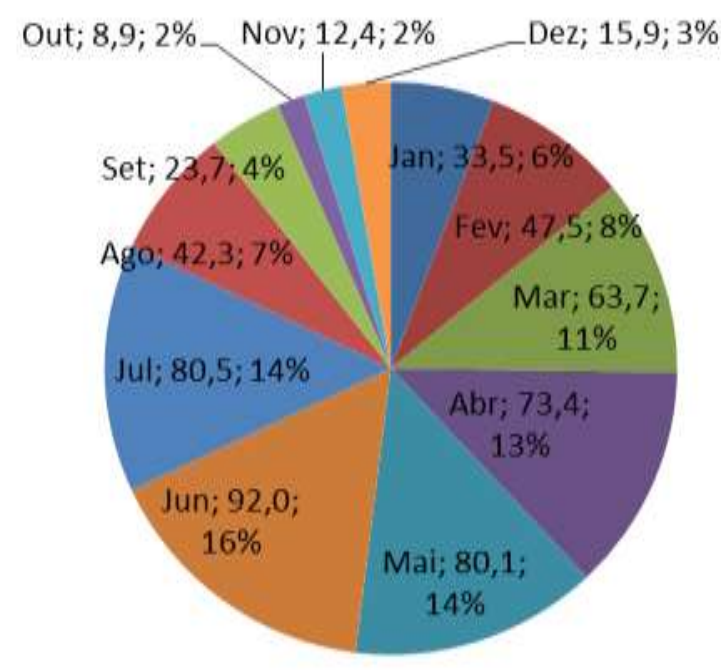

Fonte: Medeiros (2021).

O período chuvoso registra-se de fevereiro a Figura 4. As irregularidades registradas na média do período chuvoso interanual com flutuações entre 180 a $1900 \mathrm{~mm} \mathrm{ano}^{-1}$. As variabilidades anuais estão interligadas aos fenômenos de larga escala e aos fatores locais e regionais. Os anos de 1928, 1967, 1973, 1978 e 1994 foram os de maiores índices pluviais registrados, ao passo que os anos de 1938 a 1943 e de 1945 a1948 registrou-se os menores índices pluviais.

O período seco que compreende os meses de setembro a janeiro e sua representatividade na Figura 5 e da sua média de oscilações entre 0 a $360 \mathrm{~mm}$, para tanto a gestão da escassez de água deve prever a aplicação de conhecimentos necessários sobre a dinâmica dos ecossistemas de zonas secas e das tecnologias apropriadas à captação, estocagem e conservação da quantidade e qualidade das águas precipitadas em anos de abundantes aportes pluviométricos, formando significativos estoques reguladores, protegidos da evaporação, para garantir disponibilidade hídrica segura, em anos de escassez de chuvas (Silva \& Andrade 2003).

Os anos de 1915, 1923, 1933,1936 a1938, 1945, 1947, 1950, 1956, 1957, 1959,1968, 1992, 1997, 1998, 2008 e 2012 registrou-se índices pluviais abaixo dos $200 \mathrm{~mm}$ no período seco, destacamos ainda os anos 1914,1922, 1927, 1930, 1960, 1976, 1982, 1989, 1994, 2001, 2004 com índices pluviais oscilando entre $800 \mathrm{~mm}$ a $1900 \mathrm{~mm}$, nestes anos registrou-se transtornos a população e a socioeconomia local.

Os índices pluviais registrados em patamares bem abaixo da média histórica durante a estação chuvosa, ou mesmo, fora da época normal (período seco), são responsáveis por transtornos dos mais variados à socioeconomia de uma região, culminando em alguns casos com decretação de uma situação de seca, comuns no semiárido da Região Nordeste do Brasil (Anjos 2002), o que vem a corroborar com os resultados aqui discutidos. 
Figura 5. Variabilidade pluviométrica do período chuvoso e seco entre os anos de 2013 a 2016 no município de Caruaru - PE.

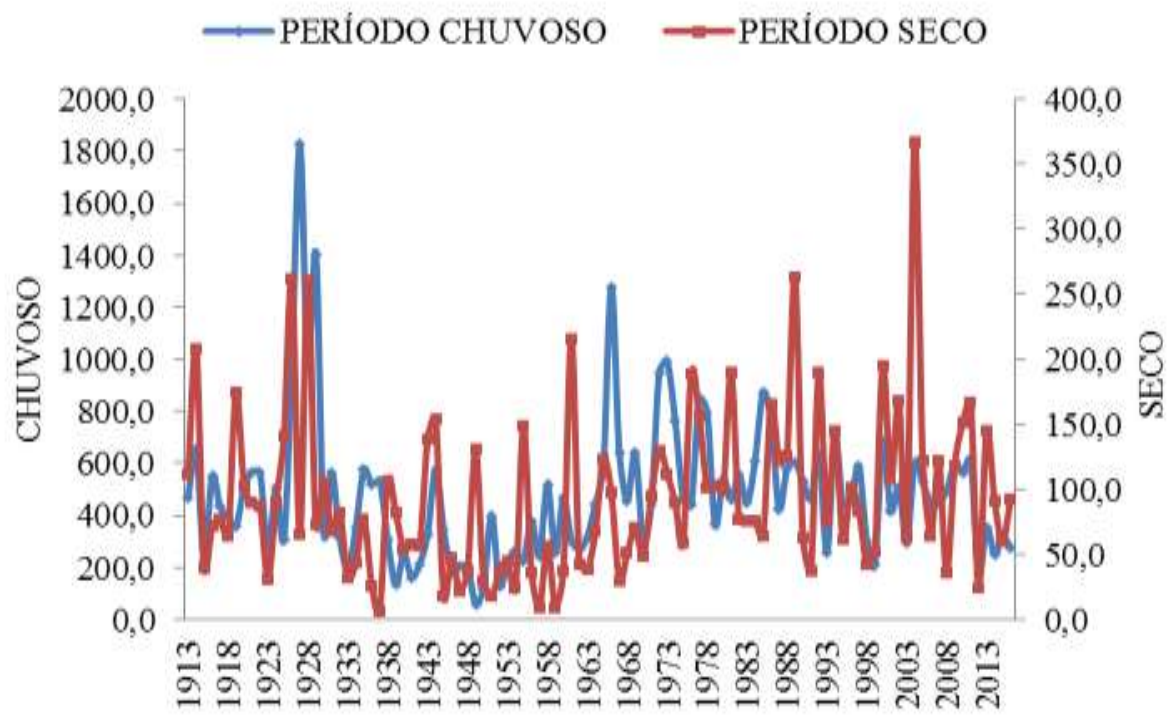

Fonte: Medeiros (2021).

O trimestre seco (outubro, novembro e dezembro) e o chuvoso (maio, junho e julho) estão representados por suas respectivas médias na Figura 6, no trimestre seco os índices pluviométricos oscilam entre 0 a $190 \mathrm{~mm}$. As flutuações do trimestre chuvoso ocorrem entre 70 a 1.160,2 mm. Estas flutuações estão interligadas aos sistemas meteorológicos atuantes em cada ano.

Figura 6. Variabilidade pluviométrica do trimestre chuvoso e seco entre os anos de 2013 a 2016 no município de Caruaru - PE.

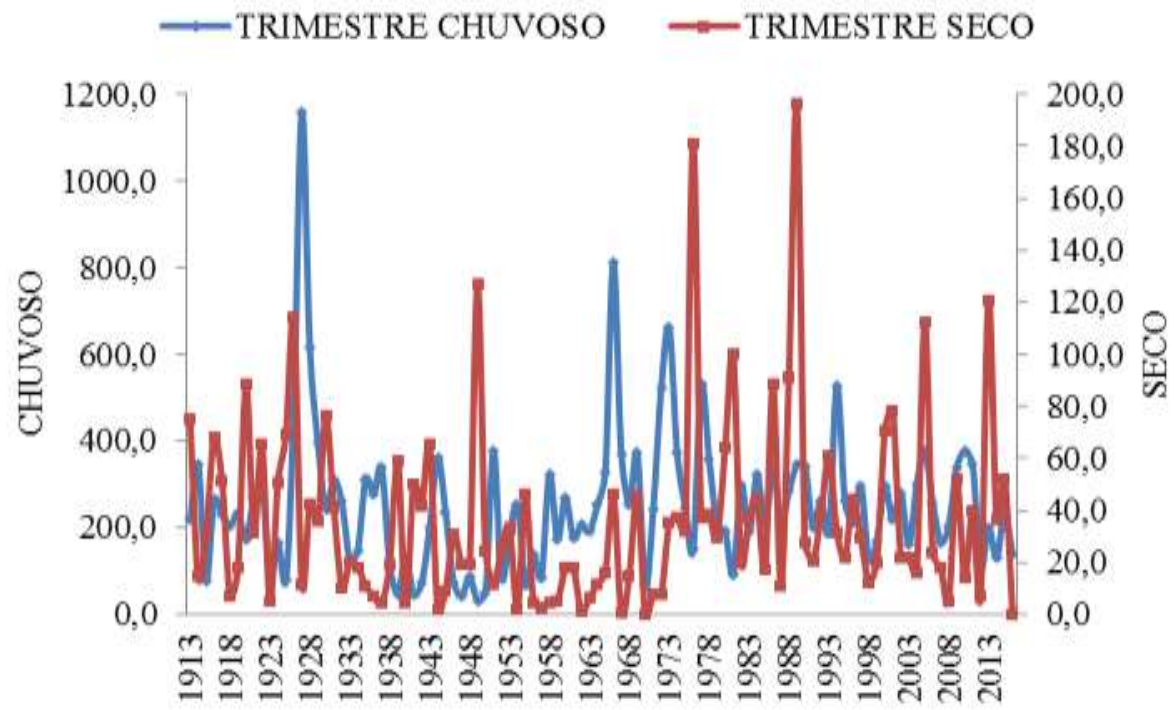

Fonte: Medeiros (2021).

A Figura 7 demostra a variabilidade pluviométrica do mês chuvoso (junho) e do mês seco outubro entre os anos de 2013 a 2016 no município de Caruaru - PE. A variabilidade mensal flui entre $0,0 \mathrm{~mm}$ a $344,4 \mathrm{~mm}$, com média de $92 \mathrm{~mm}$ para o mês 
chuvoso. No mês seco tem média de $12,1 \mathrm{~mm}$ e suas flutuações ocorrem entre 0 a 77,1 mm, estes registros com índices elevados ocorrem em dias isolados onde as formações de aglomerados convectivos formam-se e ocasionam chuvas isoladas e ocasionais.

Figura 7. Variabilidade pluviométrica do mês chuvoso e seco entre os anos de 2013 a 2016 no município de Caruaru - PE.

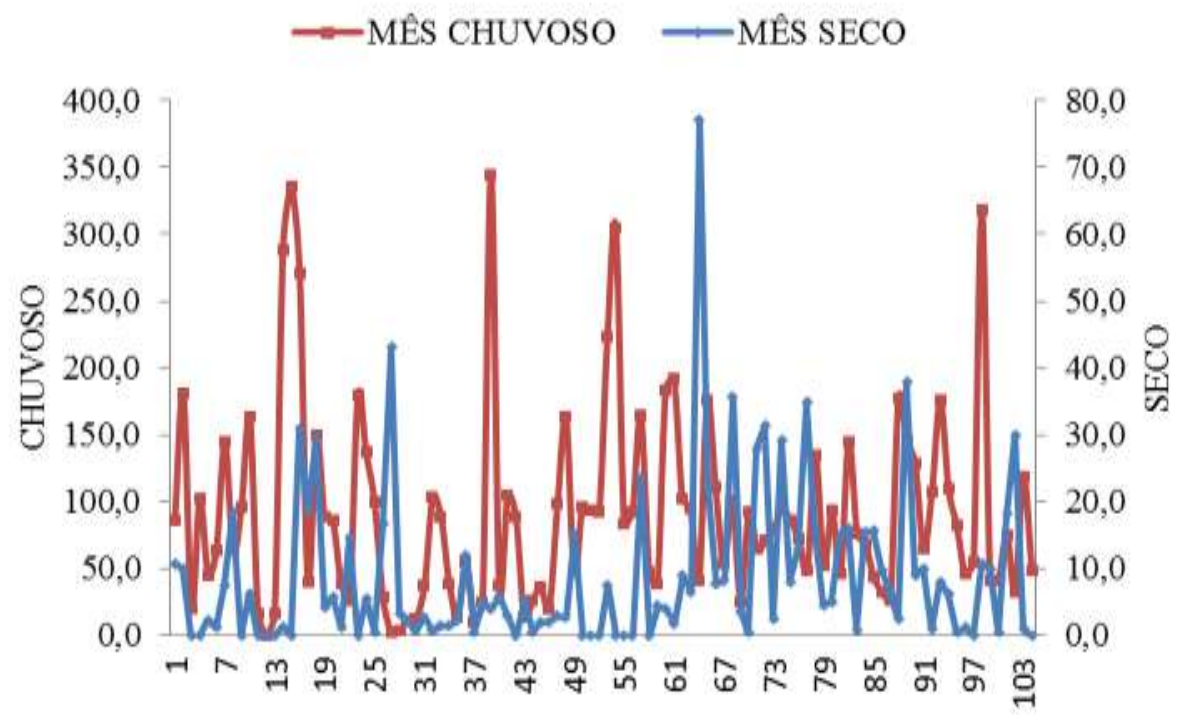

Fonte: Medeiros (2021).

Na região semiárida, mesmo com distribuições e ocorrências das chuvas irregulares e com atuações dos fatores meteorológicos, sofrendo bloqueios que impedem as regularidades, existem condições necessárias e suficientes de armazenamento, bastando para isto, não só um bom planejamento, como também um adequado monitoramento da qualidade de água em conformidade com os autores (Tenenbaum \& Medeiros 2005), estes resultados têm afinidade com o referido trabalho em desenvolvimento.

Figura 8 tem-se a distribuição da precipitação anual e média histórica para o município de Caruaru - PE, no período de 1913 a 2015. A precipitação histórica anual é de 573,4 mm. A irregularidade registrada interanual decorre das variabilidades dos sistemas sinóticos atuantes e dos efeitos locais. Nos anos de 1928, 1929, 1930, 1967, 1973, 1978, 1984, 1988, 1993, 1994, 1999, 2004, 2009, 2010 e 2011 os índices pluviométricos foram influenciados pelas atividades da La Niña com intensidade moderada a forte onde seus índices fluíram acima dos $800 \mathrm{~mm}$. Com as influencias do fenômeno de El Niño e suas flutuações de moderadas a forte onde se registrou índices pluviométricos abaixo dos $300 \mathrm{~mm}$ para os anos de 1914, 1923, 1933, 1939 1942, 1949, $1953,2012$. Destaca-se ainda que a irregularidade nos índices para o período de estudo apresenta oscilação variando entre 200 a $1900 \mathrm{~mm}$.

Marengo, Alves, Beserra e Lacerda (2011) demonstrou que as variabilidades pluviométricas que viessem registrando no semiárido deixando mais árido e com aumento da frequência de ocorrência das secas, a base de sustentação para as atividades humanas diminuirá, sendo provável o aumente do deslocamento da população às grandes cidades ou às áreas nas quais seja possível desenvolver a agricultura irrigada. 
Figura 8. Distribuição da precipitação anual e da média histórica para o município de Caruaru - PE, no período de 1913 a 2016.

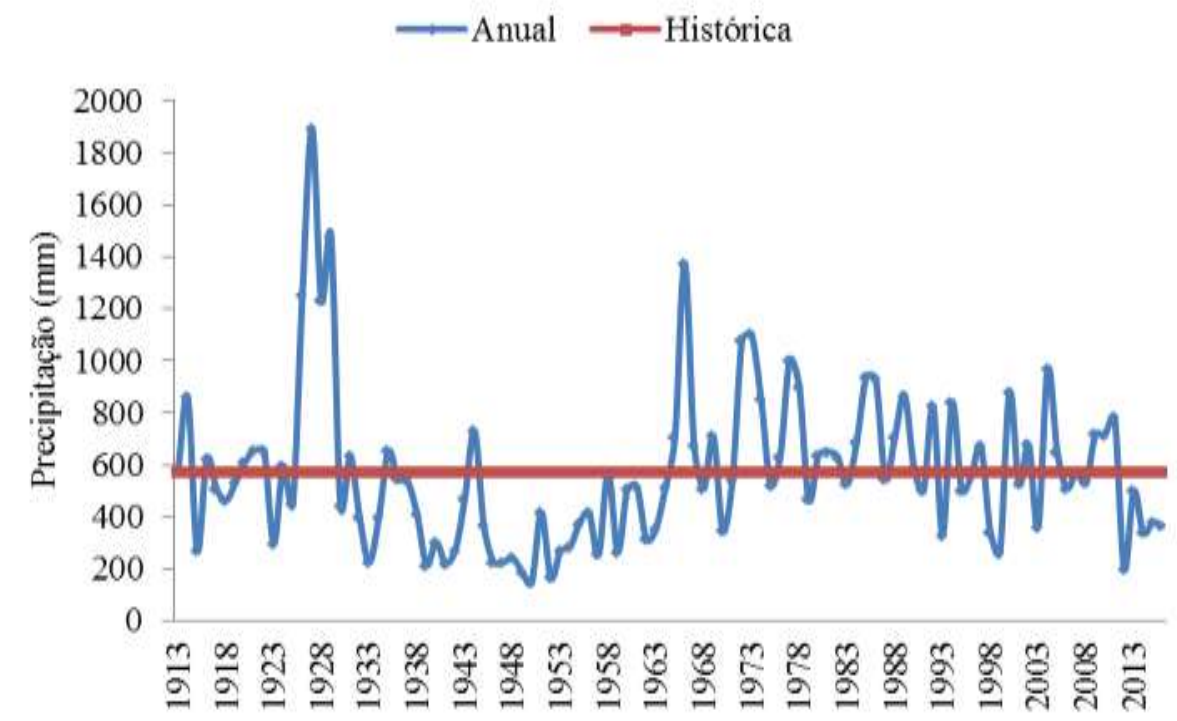

Fonte: Medeiros (2021).

Marengo e Silva Dias (2006) afirmaram que o monitoramento do regime pluviométrico da região nos últimos anos vem mostrando que a escassez dos recursos hídricos acentua os problemas socioeconômicos, em particular no final de cada ano, com os totais pluviométricos em torno da média ou abaixo da média histórica da região, fato que vem ocorrendo no município de Caruaru nas últimas três décadas.

As flutuabilidades das chuvas se estabelecem como uma das características principais do regime pluviométrico no município de Caruaru-PE. Tratando-se de uma região de clima tropical quente e úmido, com chuvas no verão e seca no inverno, Caruaru possui pluviosidade irregular, com sua magnitude alterando-se ao longo dos anos. Na Figura 9, apresenta a distribuição temporal da precipitação anual, precipitações históricas e suas flutuabilidade de $-25 \%$ e $+25 \%$ da precipitação histórica no período de 1913 a 2016, com precipitação média anual de 573,4 mm, com 104 anos de observações pluviométricas.

Figura 9. Precipitação anual e histórica, flutuabilidade de $-25 \%$ e $+25 \%$ da precipitação histórica no município de Caruaru-PE no período de 1913 a 2016.

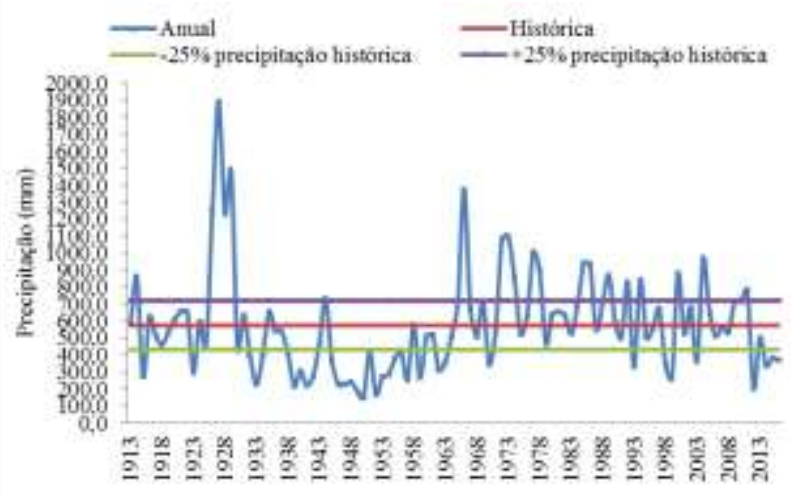

Fonte: Medeiros (2021). 
Na Figura 9, observa-se a variação dos totais anuais das chuvas históricas para o período de 1913 a 2016, onde se pode constatar que a média anual histórica é de 573,4 mm com 104 anos de observações. Durante o período analisado ocorreu grande variabilidade dos totais anuais de chuva podendo esta variabilidade ser observada nos anos de 1926(1.249,2 mm); 1927 (1.892,9 mm); 1928 (1.231,4 mm);1929 (1.477,2 mm);1966 (1.376,5 mm); 1972 (1.0805 mm); 1973 (1.103,5 mm); 1974 (853,3 mm); 1977 (1.003,2 mm); 1978 (899 mm); 1985 (939,7 mm); 1986 (932,1 mm); 1989 (869,2 mm), nos anos 1992 e 1994 choveu 826,6 e 840,2 mm, respectivamente e nos anos 2000 e 2004 seus índices pluviométricos registrados foram de 879,6 e 968,4 mm, estes índices acima da normal climatológica foram influenciados pela ação do fenômeno de larga escala La Niña com intensidade moderada a forte.

Com chuvas inferiores a 200 mm/ano registrou-se nos anos de 1949, 1950 e 1952 com chuvas registradas de 188,9; 146,8 e 165,3mm, respectivamente. De acordo com Oliveira (2001), as intensidades dos ventos variam bastante de caso a caso, sendo o El Niño mais intenso desde as observações de TSM, os de 1982/1983, 1993, 1997/1998 e de 2012/2015.

O Diagnóstico da variabilidade dos índices pluviométricos em Caruaru-PE, indica tendências de reduções desses totais pluviométricos anuais ao longo dos 104 anos, contudo, não é possível afirmar que se trate de alguma mudança climática, pois, como já se mencionou anteriormente, a variabilidade pluviométrica pode alterar essa tendência nos próximos anos.

As linhas de $-25 \%$ e $+25 \%$ demostram as variabilidades dos anos com chuvas ocorridas entre a normalidade da área de estudo, confirmando deste modo as flutuações interanuais irregulares para os índices pluviométricos no município em estudo.

Na Tabela 1 estão os valores da precipitação total anual, as médias históricas do período de 1913 a 2016 acoplado com o desvio percentual e sua respectiva classificação. A variabilidade também foi expressa na caracterização do ano normal, seco, chuvoso, muito seco, muito chuvoso, extremamente seco e extremamente chuvoso de acordo com os quantis (Xavier \& Xavier 1999). No total dos 104 anos observados, todos foram classificados como muito seco conforme exposto da tabela.

A técnica dos quantis de acordo com Xavier \& Xavier (1999) não resultou em boa metodologia para a área em estudo. 
Tabela 1. Índices pluviométricos anuais do período (1913-2016). Classificação anual, segundo método proposto por Xavier \& Xavier (1999). Muito Chuvoso (> $1.219 \mathrm{~mm})$, Chuvoso (1.048 a 1.218,9 mm), Normal (885,5 a 1.047,9 mm), Seco (769,9 a 885,6 $\mathrm{mm})$ e Muito Seco $(<770 \mathrm{~mm})$.

\begin{tabular}{|c|c|c|c|c|c|c|c|c|c|}
\hline Ano & $\begin{array}{l}\text { Prec } \\
\text { Anual } \\
(\mathrm{mm})\end{array}$ & $\begin{array}{c}\text { Prec } \\
\text { Histórica } \\
(\mathrm{mm})\end{array}$ & $\begin{array}{c}\text { Desvio } \\
\text { Percentual } \\
(\mathrm{mm})\end{array}$ & Classificação & Ano & $\begin{array}{l}\text { Prec } \\
\text { Anual } \\
(\mathrm{mm})\end{array}$ & $\begin{array}{c}\text { Prec } \\
\text { Histórica } \\
(\mathrm{mm})\end{array}$ & $\begin{array}{l}\text { Desvio } \\
\text { Percentual } \\
(\mathrm{mm})\end{array}$ & Classificação \\
\hline 1913 & 580,7 & 573,4 & 1,3 & Muito seco & 1965 & 709,1 & 573,4 & 23,7 & Muito seco \\
\hline 1914 & 860,6 & 573,4 & 50,1 & Muito seco & 1966 & 1376,5 & 573,4 & 140,1 & Muito seco \\
\hline 1915 & 269,6 & 573,4 & $-53,0$ & Muito seco & 1967 & 672,7 & 573,4 & 17,3 & Muito seco \\
\hline 1916 & 623,3 & 573,4 & 8,7 & Muito seco & 1968 & 507,1 & 573,4 & $-11,6$ & Muito seco \\
\hline 1917 & 510 & 573,4 & $-11,1$ & Muito seco & 1969 & 710,8 & 573,4 & 24,0 & Muito seco \\
\hline 1918 & 461,2 & 573,4 & $-19,6$ & Muito seco & 1970 & 344,5 & 573,4 & $-39,9$ & Muito seco \\
\hline 1919 & 532,1 & 573,4 & $-7,2$ & Muito seco & 1971 & 539,1 & 573,4 & $-6,0$ & Muito seco \\
\hline 1920 & 610,3 & 573,4 & 6,4 & Muito seco & 1972 & 1080,2 & 573,4 & 88,4 & Muito seco \\
\hline 1921 & 655,6 & 573,4 & 14,3 & Muito seco & 1973 & 1103,5 & 573,4 & 92,4 & Muito seco \\
\hline 1922 & 654,1 & 573,4 & 14,1 & Muito seco & 1974 & 853,3 & 573,4 & 48,8 & Muito seco \\
\hline 1923 & 297,8 & 573,4 & $-48,1$ & Muito seco & 1975 & 520,8 & 573,4 & $-9,2$ & Muito seco \\
\hline 1924 & 596,7 & 573,4 & 4,1 & Muito seco & 1976 & 628,1 & 573,4 & 9,5 & Muito seco \\
\hline 1925 & 452,2 & 573,4 & $-21,1$ & Muito seco & 1977 & 1003,2 & 573,4 & 75,0 & Muito seco \\
\hline 1926 & 1249,2 & 573,4 & 117,9 & Muito seco & 1978 & 899,0 & 573,4 & 56,8 & Muito seco \\
\hline 1927 & 1892,9 & 573,4 & 230,1 & Muito seco & 1979 & 466,0 & 573,4 & $-18,7$ & Muito seco \\
\hline 1928 & 1231,4 & 573,4 & 114,8 & Muito seco & 1980 & 636,5 & 573,4 & 11,0 & Muito seco \\
\hline 1929 & 1477,2 & 573,4 & 157,6 & Muito seco & 1981 & 651,2 & 573,4 & 13,6 & Muito seco \\
\hline 1930 & 439,7 & 573,4 & $-23,3$ & Muito seco & 1982 & 632,0 & 573,4 & 10,2 & Muito seco \\
\hline 1931 & 632,9 & 573,4 & 10,4 & Muito seco & 1983 & 524,0 & 573,4 & $-8,6$ & Muito seco \\
\hline 1932 & 395,4 & 573,4 & $-31,0$ & Muito seco & 1984 & 685,3 & 573,4 & 19,5 & Muito seco \\
\hline 1933 & 223,9 & 573,4 & $-61,0$ & Muito seco & 1985 & 939,7 & 573,4 & 63,9 & Muito seco \\
\hline 1934 & 397,5 & 573,4 & $-30,7$ & Muito seco & 1986 & 932,1 & 573,4 & 62,6 & Muito seco \\
\hline 1935 & 652,1 & 573,4 & 13,7 & Muito seco & 1987 & 547,6 & 573,4 & $-4,5$ & Muito seco \\
\hline 1936 & 544,1 & 573,4 & $-5,1$ & Muito seco & 1988 & 703,6 & 573,4 & 22,7 & Muito seco \\
\hline 1937 & 538 & 573,4 & $-6,2$ & Muito seco & 1989 & 869,2 & 573,4 & 51,6 & Muito seco \\
\hline 1938 & 411,1 & 573,4 & $-28,3$ & Muito seco & 1990 & 592,7 & 573,4 & 3,4 & Muito seco \\
\hline 1939 & 214,3 & 573,4 & $-62,6$ & Muito seco & 1991 & 501,3 & 573,4 & $-12,6$ & Muito seco \\
\hline 1940 & 303,9 & 573,4 & $-47,0$ & Muito seco & 1992 & 826,6 & 573,4 & 44,2 & Muito seco \\
\hline 1941 & 219 & 573,4 & $-61,8$ & Muito seco & 1993 & 329,2 & 573,4 & $-42,6$ & Muito seco \\
\hline 1942 & 270,6 & 573,4 & $-52,8$ & Muito seco & 1994 & 840,2 & 573,4 & 46,5 & Muito seco \\
\hline 1943 & 468,1 & 573,4 & $-18,4$ & Muito seco & 1995 & 502,2 & 573,4 & $-12,4$ & Muito seco \\
\hline 1944 & 731 & 573,4 & 27,5 & Muito seco & 1996 & 557,8 & 573,4 & $-2,7$ & Muito seco \\
\hline 1945 & 363,4 & 573,4 & $-36,6$ & Muito seco & 1997 & 671,5 & 573,4 & 17,1 & Muito seco \\
\hline 1946 & 227,3 & 573,4 & $-60,4$ & Muito seco & 1998 & 342,2 & 573,4 & $-40,3$ & Muito seco \\
\hline 1947 & 223,8 & 573,4 & $-61,0$ & Muito seco & 1999 & 263,2 & 573,4 & $-54,1$ & Muito seco \\
\hline 1948 & 241,5 & 573,4 & $-57,9$ & Muito seco & 2000 & 879,6 & 573,4 & 53,4 & Muito seco \\
\hline 1949 & 188,9 & 573,4 & $-67,1$ & Muito seco & 2001 & 524,8 & 573,4 & $-8,5$ & Muito seco \\
\hline 1950 & 146,8 & 573,4 & $-74,4$ & Muito seco & 2002 & 677,2 & 573,4 & 18,1 & Muito seco \\
\hline 1951 & 418,3 & 573,4 & $-27,0$ & Muito seco & 2003 & 360,3 & 573,4 & $-37,2$ & Muito seco \\
\hline 1952 & 165,3 & 573,4 & $-71,2$ & Muito seco & 2004 & 968,4 & 573,4 & 68,9 & Muito seco \\
\hline 1953 & 268,8 & 573,4 & $-53,1$ & Muito seco & 2005 & 649,0 & 573,4 & 13,2 & Muito seco \\
\hline 1954 & 283,4 & 573,4 & $-50,6$ & Muito seco & 2006 & 510,0 & 573,4 & $-11,1$ & Muito seco \\
\hline 1955 & 374,1 & 573,4 & $-34,8$ & Muito seco & 2007 & 569,3 & 573,4 & $-0,7$ & Muito seco \\
\hline 1956 & 414,5 & 573,4 & $-27,7$ & Muito seco & 2008 & 530,1 & 573,4 & $-7,6$ & Muito seco \\
\hline 1957 & 254,1 & 573,4 & $-55,7$ & Muito seco & 2009 & 717,3 & 573,4 & 25,1 & Muito seco \\
\hline 1958 & 573,6 & 573,4 & 0,0 & Muito seco & 2010 & 714,5 & 573,4 & 24,6 & Muito seco \\
\hline 1959 & 265,6 & 573,4 & $-53,7$ & Muito seco & 2011 & 781,4 & 573,4 & 36,3 & Muito seco \\
\hline 1960 & 503,8 & 573,4 & $-12,1$ & Muito seco & 2012 & 200,2 & 573,4 & $-65,1$ & Muito seco \\
\hline 1961 & 518,2 & 573,4 & $-9,6$ & Muito seco & 2013 & 499,3 & 573,4 & $-12,9$ & Muito seco \\
\hline 1962 & 312,4 & 573,4 & $-45,5$ & Muito seco & 2014 & 338,1 & 573,4 & $-41,0$ & Muito seco \\
\hline 1963 & 355,3 & 573,4 & $-38,0$ & Muito seco & 2015 & 379,4 & 573,4 & $-33,8$ & Muito seco \\
\hline 1964 & 512,8 & 573,4 & $-10,6$ & Muito seco & 2016 & 366,6 & 573,4 & $-36,1$ & Muito seco \\
\hline
\end{tabular}

Fonte: Medeiros (2021). 
Os critérios das classificações anuais foram realizados em conformidade com a Tabela 2 e as faixas dos desvios percentuais, cujos valores foram definidos pelos técnicos do INPE/CPTEC e os núcleos de meteorologia dos estados.

Tabela 2. Critérios de classificação.

\begin{tabular}{cc}
\hline Desvio Percentual & CLASSIFICAÇÃO \\
\hline $\pm 0,0$ A $25,0 \%$ & Normal \\
$\pm 25,1$ A $45,0 \%$ & Seco/chuvoso \\
$\pm 45,1$ A $70,0 \%$ & Muito seco/Muito chuvoso \\
$\pm 70,1$ A $100,0 \%$ & Extremamente seco/Extremamente chuvoso \\
\hline
\end{tabular}

Fonte: Autores.

\section{Conclusões}

O município tem potencial paisagístico e de comércio para as atividades turísticas. A chuva não se revelou elemento impeditivo à pratica do turismo. Registrou-se ano com condições favoráveis às práticas da recreação e do lazer. O mês de junho com chuvas moderadas a forte em fins de semana podem ter prejudicado totalmente as atividades turísticas de campo, nos demais meses os índices pluviais indicaram boas condições para o seu desenvolvimento turístico rural e urbano.

Com distribuição pluvial irregular ao longo do ano grande parte ocorreu no verão, com ativa participação e contribuição dos sistemas atmosféricos: ZCIT, VCAN, dos efeitos locais e regionais, além da contribuição das linhas de instabilidades e de áreas de baixa pressão acarretando chuvas moderadas a forte com duração de 7 a 8 horas de ocorrência.

No período seco, evidenciou-se redução na quantidade das precipitações e registraram-se chuvas isoladas e ocasionais de magnitude variada em curto intervalo de tempo.

Os sistemas de bloqueios deixando o céu azul ocorreram em maior escala, sem constantes interrupções dos sistemas locais e regionais. Esses sistemas garantiram estabilidade atmosférica e bom tempo, excelentes à prática de atividades de turismo, recreação e lazer urbano/rural.

Quanto as oscilações dos índices térmicos, não se verificou maiores dificuldades e/ou condições inibitórias que impedissem as práticas turísticas.

\section{Referências}

Alvares, C. A., Stape, J. L., Sentelhas, P. C., Gonçalves, J. L. M., \& Sparovek, G. (2013). Köppen's climate classification map for Brazil. Meteorologische Zeitschrift, http://dx.doi.org/10.1127/0941-2948/2013/0507

Anjos, B. L. (2002). Os episódios do El Niño de 1997/98 e La Niña de 1998/99 e as configurações da precipitação e insolação na cidade de Teresina. In: XII Congresso Brasileiro de Meteorologia, Anais: Foz de Iguaçu - PR.

APAC. Agencia Pernambucana de Água e Clima. 2017.

Barbiére, E. B. (1981). O fator climático nos sistemas territoriais de recreação: uma análise subsidiária ao planejamento na faixa litorânea do estado do Rio de Janeiro. Revista Brasileira de Geografia. 43(2), 145-265, Rio de Janeiro.

Bartholo, R, Sansolo, D. G, \& Bursztyn, I. Turismo de Base Comunitária. www.iIvt-rj.net/ivt/bibli/LivroTBC.pdf .

Beni, M. C. (2001). Análise estrutural do turismo. Senac (5a ed.).

Besancenot, J-P. Climat et tourisme. Masson, 1990.

Caram, R. O. (2007). Reconstrução de séries e análise geoestatística da precipitação no Estado de Minas Gerais. Dissertação (Magister Scientiae) - Universidade Federal de Viçosa. 
Dias, R. (2003). Planejamento do Turismo: Política e Desenvolvimento do Turismo no Brasil. São Paulo: Atlas.

Köppen, W., \& Geiger, R. (1928). “Klimate der Erde. Gotha: Verlag Justus Perthes”. Wall-map 150cmx200cm.

Marengo, J. A., Alves, L. M., Beserra, E. A., \& Lacerda, F. F. (2011). Variabilidade e mudanças climáticas no semiárido brasileiro. Recursos hídricos em regiões áridas e semiáridas. INSA. 303 - 422. Campina Grande-PB.

Marengo, J., \& Silva Dias, P. (2006). Mudanças climáticas globais e seus impactos nos recursos hídricos. Capitulo 3 em Águas Doces do Brasil: Capital Ecológico, Uso e Conservação. 63-109, Eds. A. Rebouças, B., Braga e J. Tundisi. Editoras Escrituras, SP.

Medeiros, R. M., Holanda, R. M., Viana, M. A., \& Silva, V. P. Climate classification in Köppen model for the state of Pernambuco - Brazil. Revista de Geografia (Recife). 35, 219 - 234, 2018

medeiros, R. M. (2016). Estudos dos fatores provocadores de chuvas no estado de Pernambuco - Brasil.

Medeiros, R. M., Sousa, F. A. S., \& Gomes Filho, M. F. (2014). Variabilidade espaço temporal da precipitação na área da bacia hidrográfica do rio Uruçuí Preto - PI. ANAIS do VI Congresso de mudanças climáticas em recife. 2014.

Medeiros, R. M., Borges, C. K., \& Patricio, M. C. M. (2012). Contribuição dos elementos meteorológicos ao turismo rural no semiárido paraibano - Cabaceiras In: Comunidades, natureza e cultura no turismo. 01. Editora João Pessoa: Universitária - UFPB, p. 1199-1213.

Moulin, G. D. (2015). Técnicas de entropia e de geoestatística no dimensionamento de redes pluviométricas. Dissertação (Mestre em Engenharia Ambiental) Universidade Federal do Espírito Santo.

Oliveira, R. C. S., Medeiros, R. M, Silva, V. M. A., \& Brito, J. I. B. (2013). Subsídios das informações meteorológicas ao turismo do município de Lagoa Seca, PB In: Anais do Congresso Nacional de Educação Ambiental e do Encontro Nordestino de Biogeografia: Educação e cooperação pela água para a conservação da biodiversidade. (3a ed.), Editora da UFPB, 2013, 3, 586-596.

Oliveira, G. S. (2001). O El Niño e Você: o fenômeno climático. Editora Transtec

Silva, H. P., \& Andrade, S. M. (2003). Brasil um país de terras secas: problemática, dimensão e alternativas de tecnologias apropriadas para o semiárido. In: Cirelli, A. F., Abraham, E. El agua en Iberoamérica: Aspectos de la problemática de las tierras secas. CYTED XVII. Aprovechamento y gestión de los recursos hídricos. p.55-64. 2003.

Sudene. (1990). Superintendência de Desenvolvimento do Nordeste - Dados pluviométricos mensais do Nordeste - Série pluviometria 5. Estado de Pernambuco. Recife, $239 \mathrm{p}$.

Tele, A. G. S., Matos, R. M., \& Medeiros, R. M. A Influência da meteorologia ao turismo religioso nos festejos de município de Barbalha - CE. 1 ed. João Pessoa Paraíba: Universitária1, 294-305.

Tenenbaum, R. V. O., \& Medeiros, R. M. (2005). Variabilidade anual da precipitação pluvial e condições de armazenamento de água de chuva no município de São Raimundo Nonato, Piauí. In: $5^{\circ}$ Simpósio Brasileiro de Captação e Manejo de Água de Chuva. Teresina - PI.

Tucci, C. E. M. (2001). Hidrologia: ciência e aplicação. Ed. Universidade/UFRGS: ABRH.

Xavier, T. M. B. S., \& Xavier A. F. S. (1999). Caracterização de períodos secos ou excessivamente chuvosos no estado do Ceará através da técnica dos quantis. Revista Brasileira de Meteorologia, 14(2), 63-78. 